\title{
EFFECT OF INTERNAL ELEMENTS OF THE STEAM TURBINE EXHAUST HOOD ON LOSSES
}

\author{
Michal HOZNEDL, Aleš PACÁK, Ladislav TAJČ• \\ Abstract: The document deals with the flow in the exhaust hood of a single flow \\ steam turbine. The effect of the shape of the external case of the hood and the \\ position and dimensions of the internal reinforcements on the energy loss \\ coefficient is evaluated. Using this coefficient, it is possible to determine the gained \\ or lost output in the diffuser and the entire exhaust hood at a known flow and \\ efficiency of the last stage. Flow research in the exhaust hood was performed \\ especially using numeric simulations; some variants were verified experimentally in \\ the aerodynamic wind tunnel.
}

\section{INTRODUCTION}

The axial-radial exhaust hood of a steam turbine serves for transferring of steam from the last stage into the condenser. The functional part of the exhaust hood is the diffuser, the task of which is to change the outlet velocity from the last stage to pressure and thus extend the expansion line of the last stage and its output. Due to the fact that the flow must turn by $90^{\circ}$ in a very short distance, significant losses occur here, frequently connected with flow tearing from the wall. Other losses are caused by the effect of the large number of reinforcements in the hood space.

At SKODA POWER, there is an extensive programme of exhaust hood research. After the completion of the research of two flow arrangement exhaust hoods [1], [2], research of single flow exhaust hoods was approached. The knowledge from the two flow hood research became the basis for the newly researched single flow hoods. Many works were performed that aimed especially at the optimisation of the diffuser shape, in which up to $90 \%$ of the total value of losses are created, the works were presented in [3] and [5]. The work [4] deals with a similar topic. A lot of attention was paid to the research of the influence of the flow through the tip clearance and blowing into the diffuser wall - [6]. The effect of the blowing in is positive in certain cases, turbulence and stabilisation of the boundary layer on the wall takes place - [7]. Theoretical guidelines for diffuser shaping and other possibilities of loss decreasing are described in detail in [8].

The performed numerical simulations focused on determining the effect of reinforcements and partitions on the loss coefficient. One of the main goals was the shape modification of the locking plate. Also the effect of the slope of the front wall and the influence of the shift of the external hood case was calculated. All variants were entered with real conditions of the single flow exhaust hood for a $72 \mathrm{MW}$ turbine.

\footnotetext{
- Michal Hoznedl, ŠKODA POWER s.r.o., Tylova 1/57, Plzeň, 30128, michal.hoznedl@doosan.com Aleš Pacák, ŠKODA POWER s.r.o., Tylova 1/57, Plzeň, 30128, ales.pacak@doosan.com Ladislav Tajč, ŠKODA POWER s.r.o., Tylova 1/57, Plzeň, 30128, ladislav.tajc@doosan.com
} 
The single flow exhaust hood model measurement took place in the aerodynamic wind tunnel. The results found using CFD and experimentally were compared.

\section{NUMERIC MODEL DESCRIPTION}

For calculations of variants designated as CFDR, the real 3D shape of the exhaust hood of the steam turbine was considered. Compressible water steam was used as the medium. The inlet parameters are given by the real components of velocities, variable along the height of the inlet profile. The mean value of the axial component of the outlet velocity reached $150 \mathrm{~m} \cdot \mathrm{s}^{-1}$. At the outlet, constant static pressure was prescribed. The calculation section at the outlet is extended by $2.5 \mathrm{~m}$ for reason of the real distribution of the static pressure in the real outlet cross section.

In the event that the result from experimental measuring and the calculation of the experimental exhaust hood model were compared, the same edge conditions as with the experiment were used. Such variants were designated as CFDM. Air was used as the medium and the velocity component profiles at the inlet were determined by measuring. The mean value of inlet velocity into the hood is $29 \mathrm{~m} \cdot \mathrm{s}^{-1}$. At the outlet, atmospheric pressure is set in accordance with the experiment.

The FLUENT commercial program with the set Spalart-Allmaras turbulence model and with second orders of precision in space and time was used for the calculations.

\section{EXPERIMENTAL TEST RIG DESCRIPTION}

The design of the entire wind tunnel is in Figure 1:

Pos 1. - air intake

Pos 2. - noise suppressor

Pos 3. - flow mass regulation

Pos 4. - compressor

Pos 5. - flaps

Pos 6. - turbulence generators (sieves)

Pos $7 . \quad$ - Venturi nozzle

Pos 8. - stationary blade cascade

Pos 9. - model of single flow exhaust hood

Air is drawn through the entire wind tunnel to the model of the single flow exhaust hood. The model is made from acrylic glass in order to use some visualization methods and to simplify changing measured alternatives. The model is scaled 1:4.3 of the actual Skoda exhaust hood. Outlet pressure is presumed to be atmospheric pressure. Using the experimental test rig, it is possible to monitor the energy losses in the axial-radial diffuser and the entire exhaust hood. At the inlet, $\mathrm{Ma}=0.1$ was achieved. The stationary blades before the inlet into the measuring space simulate the speed arrangement after the turbine last stage. The standard combined uncertainty reaches a value of $1.6 \%$ in all measured points. 


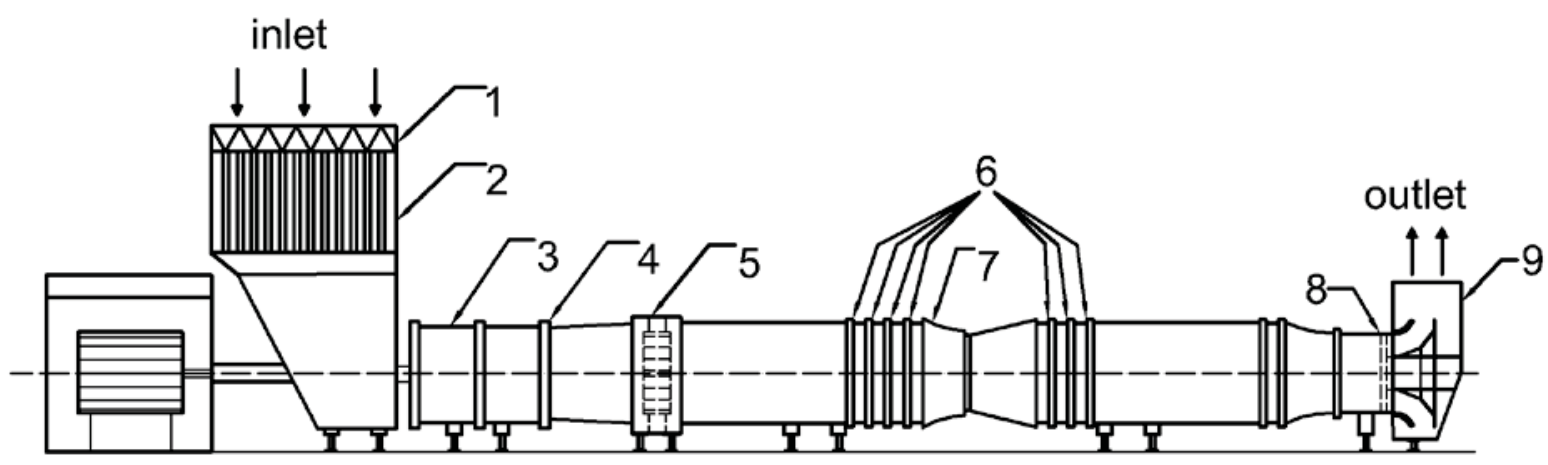

Figure 1: Experimental test rig

The actual model of the exhaust hood is in Figure 2. The front view of the experiment is in Figure 3.

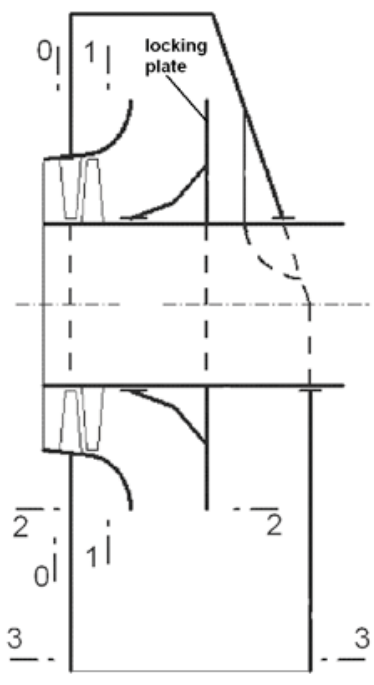

Figure 2: Measuring plane designation

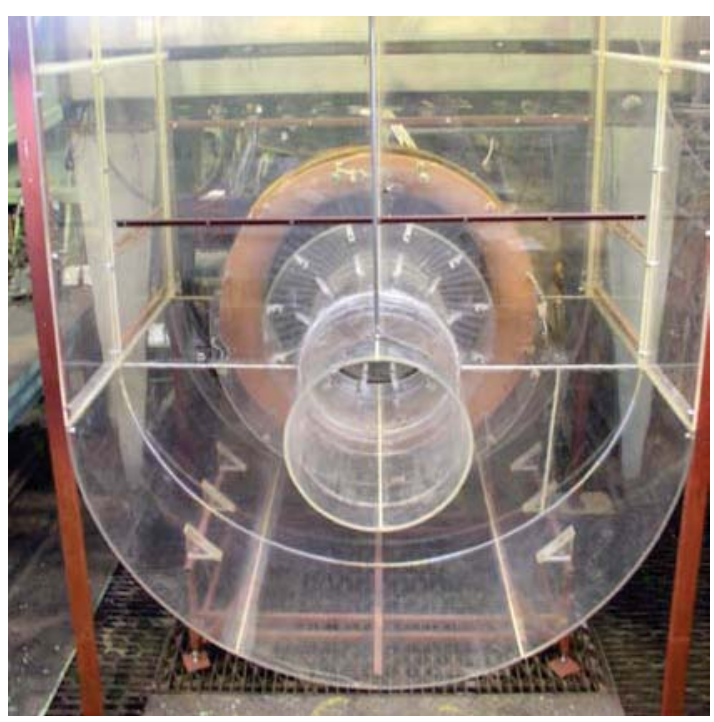

Figure 3: Front view

\section{Data evaluation}

The loss coefficient of the diffuser is determined from the static pressures between planes 1 and 2 , the loss coefficient of the exhaust hood between planes 1 and 3 . Enthalpy drops are in Figure 4.

$$
\zeta_{D}=\frac{1-\left(\frac{p_{D}}{p_{0 t}}\right)^{\frac{\kappa-1}{\kappa}}}{1-\left(\frac{p_{0}}{p_{0 t}}\right)^{\frac{\kappa-1}{\kappa}}}=\frac{h_{D}}{h_{0}}
$$

Diffuser loss coefficient

$$
\zeta_{H}=\frac{1-\left(\frac{p_{H}}{p_{0 t}}\right)^{\frac{\kappa-1}{\kappa}}}{1-\left(\frac{p_{0}}{p_{0 t}}\right)^{\frac{\kappa-1}{\kappa}}}=\frac{h_{H}}{h_{0}}
$$

Exhaust hood loss coefficient

In [6] is said that information transfer from the experiment on the part is possible, namely using the correction coefficient for the Mach number. Its effect on the losses begins to show significantly only from $\mathrm{Ma}>0.4$, see Figure 5. 


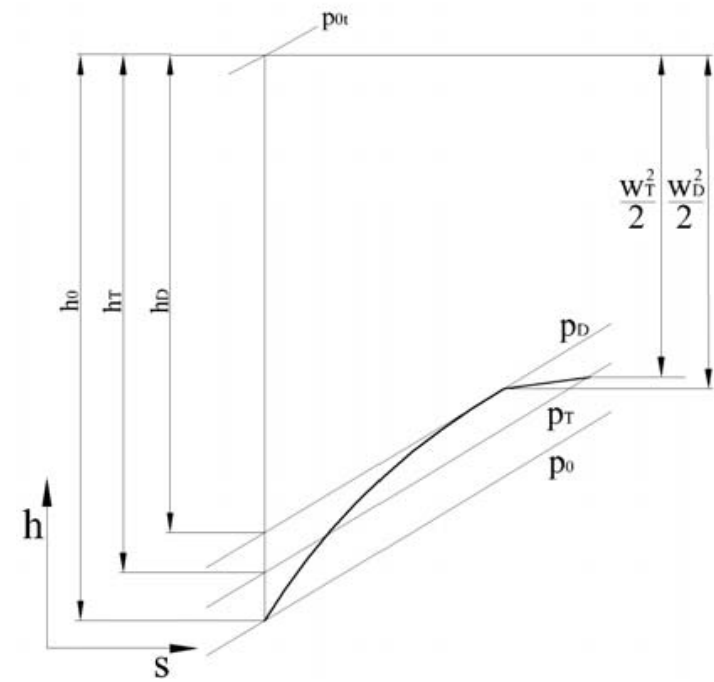

Figure 4: Enthalpy gradients in the hood

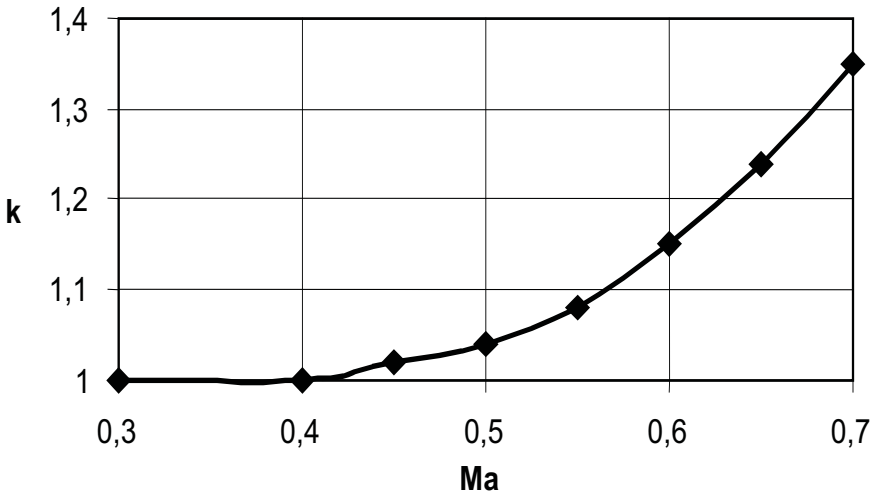

Figure 5: Mach number correction coefficient

\section{DESCRIPTION OF DESIGNED VARIANTS}

15 hood shape variants were designed. The main emphasis was put on the shaping of the locking plate, because in the space behind it an area is created, in which flow separation and strong whirling take place. The purpose of the modifications was to remove these areas using internal structures. Another massive vortex is created above the deflector, so variants with the goal of eliminating this vortex were also designed. Variant A was used as the reference existing design, to which all other variants were related. The description of variants is in Table 1 ; figures showing the individual variants are in Table 2.

\begin{tabular}{|c|c|c|c|}
\hline Variant A & \multicolumn{3}{|l|}{ Basic layout exhaust hood } \\
\hline Variant B & \multicolumn{3}{|c|}{ Exhaust hood with locking plate shape modification } \\
\hline \multirow[t]{2}{*}{ Variant C } & \multirow[t]{2}{*}{$\begin{array}{l}\text { Exhaust hood with lateral } \\
\text { partitions in the locking } \\
\text { plate area }\end{array}$} & Variant C1 & $\begin{array}{l}\text { Exhaust hood with a lateral } \\
\text { partition under the parting } \\
\text { plane }\end{array}$ \\
\hline & & Variant C2 & $\begin{array}{l}\text { Exhaust hood with a lateral } \\
\text { partition above the parting } \\
\text { plane }\end{array}$ \\
\hline Variant D & \multicolumn{3}{|c|}{ Exhaust hood with shifted external body -4 shifts } \\
\hline \multirow[t]{2}{*}{ Variant E } & \multirow{2}{*}{$\begin{array}{l}\text { Exhaust hood with } \\
\text { longitudinal partitions and } \\
\text { rotor opening modification }\end{array}$} & Variant E1 & $\begin{array}{l}\text { Exhaust hood with full } \\
\text { longitudinal partitions }\end{array}$ \\
\hline & & Variant E2 & $\begin{array}{l}\text { Exhaust hood with partially } \\
\text { open longitudinal partitions }\end{array}$ \\
\hline Variant F & \multicolumn{3}{|c|}{ Exhaust hood with changed rear wall slope $\varphi-4$ slopes } \\
\hline Variant G & \multicolumn{3}{|c|}{$\begin{array}{l}\text { Exhaust hood with optimised shape area at the trailing edge of the locking } \\
\text { plate }\end{array}$} \\
\hline Variant $\mathrm{H}$ & \multicolumn{3}{|c|}{ Optimally shaped exhaust hood } \\
\hline
\end{tabular}

Table 1: Alternatives description 
The flow in the entire hood is characteristic due to the creation of four vertical vortices, of which two are created in the front and two in the rear part of the hood. The medium flow divides into two parts immediately after leaving the diffuser. A part of the flow goes around the locking plate (vortex 1 ) and another part of the flow goes around the deflector (vortex 2), where the largest losses occur due to the strong whirling of the flow, see Figure 6. The flow character described above was found based on many CFD calculations. In Figure 7 the vector field of velocities in the vertical axis section through the hood is shown, where both vortices are apparent. The effort to eliminate vortex 1 first led to using the generally shaped locking plate- variant B. This variant proved to be efficient, but only hard to use in practice due to the shape demands.

Vertical reinforcements were to prevent the medium flow behind the locking plate, designed in variant $\mathrm{C} 1$ (partition under the parting plane level) and in variant $\mathrm{C} 2$ (partition under and above the parting plane level).

For purpose of removing vortex 2, 4 geometries were tested, where the external case of the hood was shifted against the fixed last stage. Shift $x$ is related to the length of the last blade $I_{0}$. The minimum value of the ratio $x / I_{0}=0$ was achieved in the case that the front wall of the hood tangentially followed the deflector. The maximum value was for the case of existing body design.

Further designed variants were vortex structure suppressors, located on both sides of the hood under the parting plane, see variants E1 - exhaust hood with full partitions and E2 - with partially open partitions. Their purpose was especially breaking the two screw vortices coming from the upper part of the hood and making the outlet velocity field more even for reason of unified stress and thermal load of the pipes in the condenser. These variants were modelled together with the vertical partition under the parting plane. Its task is to prevent the steam flowing from one half of the hood into the other. Also a modification of the rotor opening was modelled. Its purpose is lowering the area under this opening, in which flow separation takes place.

In the case of variant $F$, a series of slopes of the rear wall was designed. By the slope, it is possible to change the flow cross section and the amount of steam into the space after the locking plate, which is always problematic from the loss coefficient standpoint, see Figure 6. Except for the sloped rear wall that has a slope of $\varphi=20^{\circ}$ with variant $A$, the geometry did not contain any other internal modifications.

Variant $G$ especially follows variant $B$, modified so that it is possible to technologically manage the shaping in question and with the lowest production costs possible.

Variant $\mathrm{H}$ contains the final design of the exhaust hood with many modifications affecting the flow positively from the loss standpoint. The design capabilities and strength criteria are considered at the same time. 


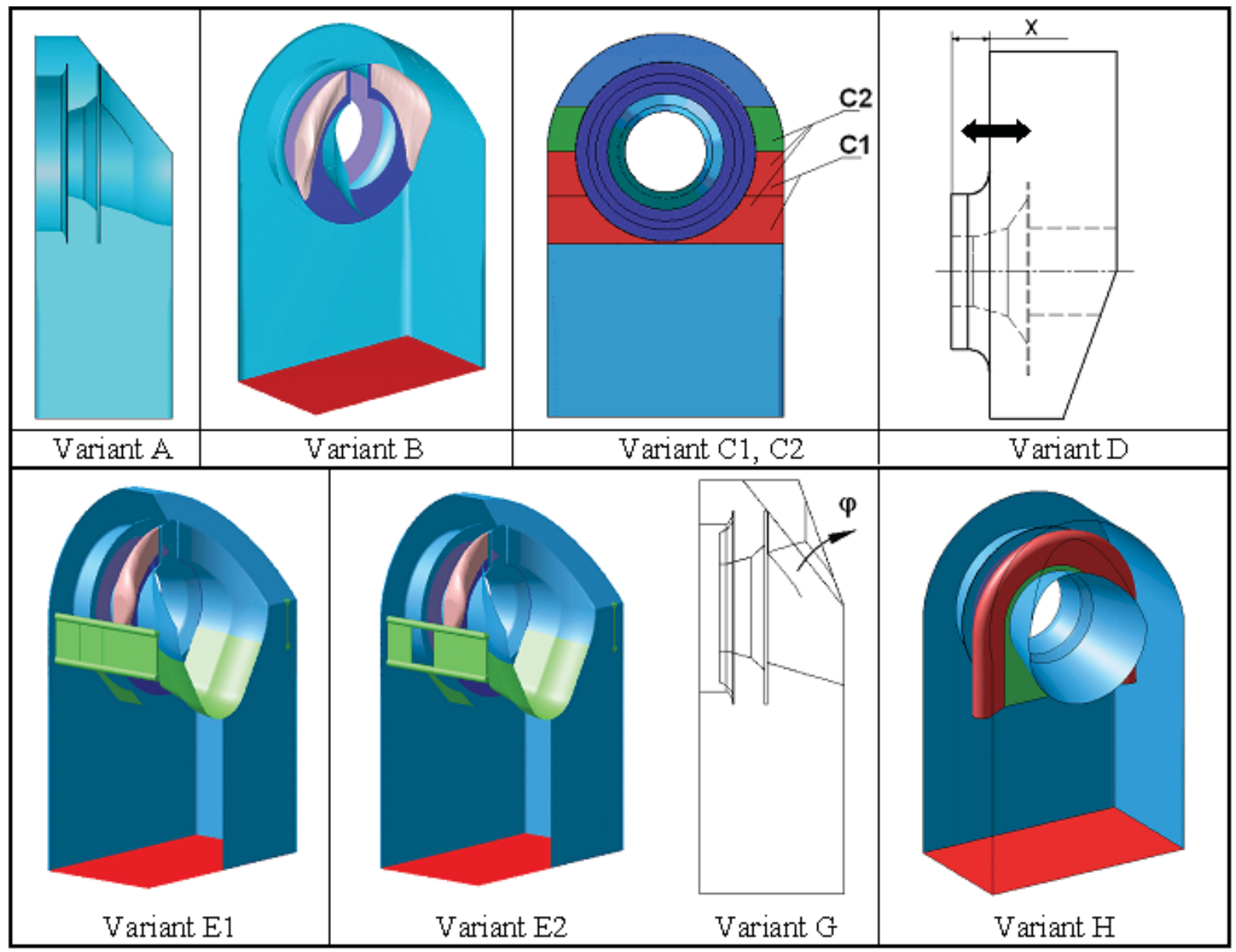

Table 2: Alternatives visualisation

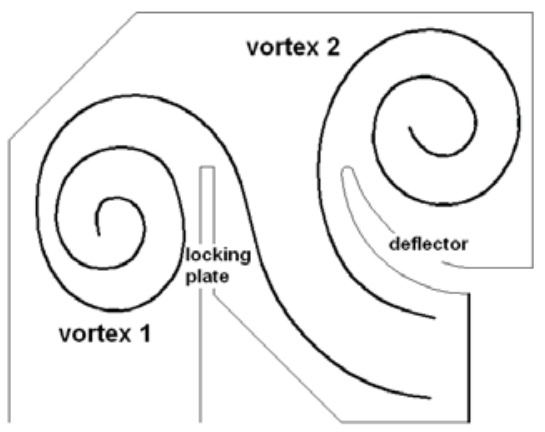

Figure 6: Schematic vortex indication

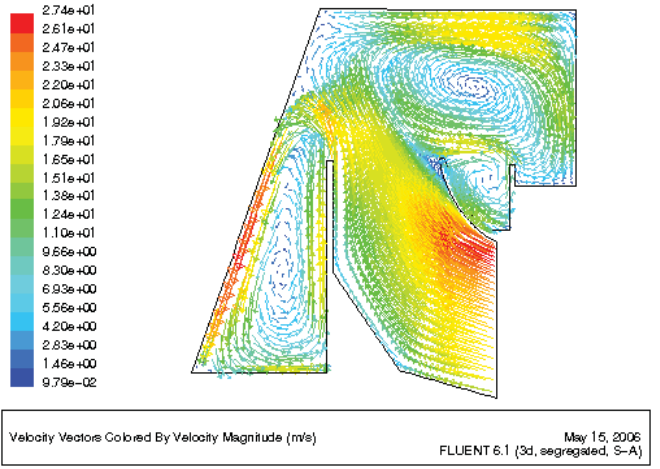

Figure 7: Flow in the hood - CFD simulation

\section{Calculation and measurement Results}

What follows are the results of the flow calculations in the real exhaust hood with real edge conditions and medium parameters or flow calculation results on the exhaust hood model where the same real conditions as with the experiment are used. 


\section{Variant A}

Variant $A$ is designed as a reference case of the body without reinforcements.

\begin{tabular}{|c|c|c|c|}
\hline \multirow{4}{*}{$\begin{array}{l}\varangle \\
\dot{\pi} \\
>\end{array}$} & & $\zeta_{\mathrm{D}}$ & $\zeta_{H}$ \\
\hline & $\mathrm{CFD}_{\mathrm{R}}$ & - & 1.000 \\
\hline & CFD $_{M}$ & 1.000 & 1.000 \\
\hline & Experiment & 1.000 & 1.000 \\
\hline
\end{tabular}

Table 3: Variant A loss coefficient

The difference between the measured variant and its calculated equivalent is minimal. The difference between the calculation of real geometry with real medium parameters and the model parameters is significant. This may be caused by the influence of the higher Reynolds number with alternative CFDR. The compressibility of the flow has no significant effect in this case; the level of the Mach number reaches values $M a=0.35$. The main reason of the difference, however, is the fact that with case CFD $_{R}$ no flow

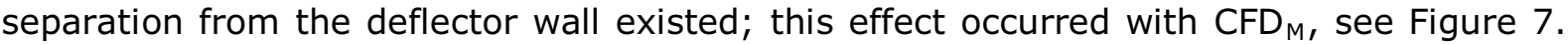
Flow separation and the related whirling may cause losses of up to tens of percent, see [5].

\section{Variant B}

Using the shaping, whirling in the area after the locking plate was limited. Vortices are successfully suppressed in the area after the locking plate and this causes a significant decrease of the loss coefficient. A disadvantage of the solution is the design demand of such a design. In Figure 8 there is the design of the general area contour after the locking plate and in Figure 9 there are the resulting contours of the velocity field after the application of the shape area. Removal of vortex structures after the board is apparent. In Table 4 there is the resulting loss coefficient. Thanks to the aforementioned reasons, only the CFD calculation with the real hood was performed; the calculation of the model and experimental measurement were not performed.

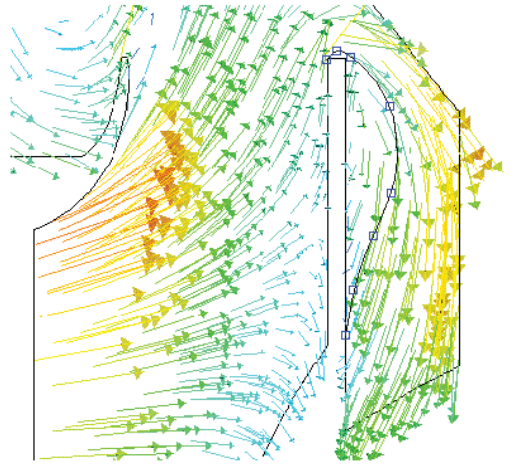

Figure 8: General area shape design

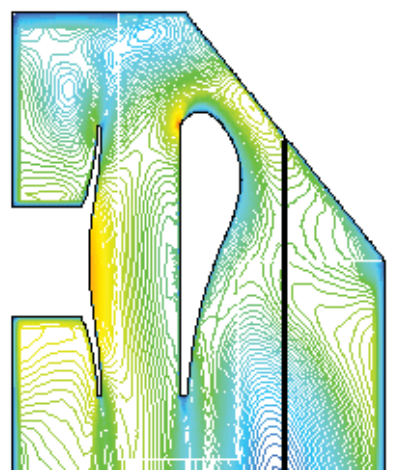

Figure 9: Velocity contours after modification

\begin{tabular}{|l|l|l|l|}
\hline \multirow{3}{*}{$\infty$} & & $\zeta_{D}$ & $\zeta_{H}$ \\
\cline { 2 - 4 }$\dot{N}$ & CFD $_{R}$ & - & 0.867 \\
\cline { 2 - 4 }$>$ & CFD $_{M}$ & - & - \\
\cline { 2 - 4 } & Experiment & - & - \\
\hline
\end{tabular}

Table 4: Variant B loos coefficients 


\section{Variants C1 and C2}

C1: Another effort for limiting the vortex after the locking plate is to use a partition expanding the locking plate. This causes a limitation of the vortex structures in the area just after the locking plate, but the fluid also gets into this area over the edges of the partitions. A vortex is created here that collides with the second vortex, created still before the locking plate. The result is an acute increase of losses.

C2: Thanks to the location of the partition above the parting plane, the flow into the area after the locking plate is limited. Such an intervention breaches the flow in the entire area, chaotic movement of particles is created here and the area conditions for flowing steam are breached.

From Table 5 it results that variants with the model exhaust hood were not calculated or measured again. The reason was the increase of the loss coefficient that showed the variants in question as having no promise for further research.

\begin{tabular}{|c|c|c|c|c|}
\hline \multirow{8}{*}{$\begin{array}{l}u \\
\frac{1}{0} \\
\frac{\pi}{2} \\
\frac{1}{\pi} \\
>\end{array}$} & \multirow{4}{*}{$\tilde{u}$} & & $\zeta_{D}$ & $\zeta_{H}$ \\
\hline & & $\mathrm{CFD}_{\mathrm{R}}$ & - & 1.149 \\
\hline & & $\mathrm{CFD}_{M}$ & - & - \\
\hline & & Experiment & - & - \\
\hline & \multirow{4}{*}{$\mathcal{U}$} & & $\zeta_{D}$ & $\zeta_{H}$ \\
\hline & & $C F D_{R}$ & - & 1.467 \\
\hline & & $\mathrm{CFD}_{\mathrm{M}}$ & - & - \\
\hline & & Experiment & - & - \\
\hline
\end{tabular}

Table 5: Variant C1 and C2 loss coefficients

Variant D

Using the shift of the external wall, vortex 2 was eliminated. For the reason of preserving the flow sections, a part of the case after the locking plate was also moved, which led to an increase of losses due to the enlargement of vortex 1, see Table 6.

\begin{tabular}{|c|c|c|c|c|}
\hline \multirow{13}{*}{$\begin{array}{l}0 \\
\frac{1}{2} \\
\frac{0}{0} \\
\frac{1}{2} \\
\frac{10}{>}\end{array}$} & \multirow{4}{*}{$\begin{array}{ll}\| \prime & 8 \\
\sum_{x}^{\circ} & 0\end{array}$} & & $\zeta_{\mathrm{D}}$ & $\zeta_{H}$ \\
\hline & & $\mathrm{CFD}_{\mathrm{R}}$ & - & - \\
\hline & & $\mathrm{CFD}_{\mathrm{M}}$ & 1.123 & 1.170 \\
\hline & & Experiment & 1.218 & 1.409 \\
\hline & \multirow{3}{*}{ 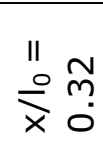 } & $\mathrm{CFD}_{\mathrm{R}}$ & - & - \\
\hline & & CFD $_{M}$ & 1.026 & 1.063 \\
\hline & & Experiment & 1.073 & 1.221 \\
\hline & \multirow{3}{*}{$\begin{array}{cc}\| & 0 \\
0 & 0 \\
\times & 0 \\
x & 0\end{array}$} & $\mathrm{CFD}_{\mathrm{R}}$ & - & - \\
\hline & & $\mathrm{CFD}_{M}$ & 1.028 & 1.064 \\
\hline & & Experiment & 1.067 & 1.124 \\
\hline & \multirow{3}{*}{$\begin{array}{cc}\| & \hat{x} \\
& 0 \\
x & 0\end{array}$} & $\mathrm{CFD}_{\mathrm{R}}$ & - & - \\
\hline & & $\mathrm{CFD}_{\mathrm{M}}$ & 1.000 & 1.000 \\
\hline & & Experiment & 1.000 & 1.000 \\
\hline
\end{tabular}

Table 6: Variant D loss coefficients

\section{Variants E1 and E2}

The main goal is the improvement of the velocity field at the inlet into the condenser by breaking the screw vortices created along both sides of the hood. 
E1: Partitions cause better alignment of the velocity field at the condenser inlet. The shaping of the rotor opening has a positive influence on the loss coefficient. In comparison with variant $B$, a slight rise of losses occurred.

E2: The purpose of the solution is to allow the flow leaving the axial-radial diffuser in the radial direction passing through the open partition into the area behind this partition. It has shown that, thanks to such a solution, the vortices are not suppressed as much as with variant E1. The use of the partitions is somewhat advantageous; however it does not make sense making the partitions divided.

Table 7 shows a comparison of the calculation and experiment results. The difference of the results between $C_{R D}$ and $C_{R D}$ is caused by the size of the area with the flow separated from the deflector as well as with variant $D$.

\begin{tabular}{|c|c|c|c|c|}
\hline \multirow{8}{*}{ 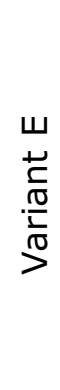 } & \multirow{4}{*}{ 푸 } & & $\zeta_{D}$ & $\zeta_{H}$ \\
\hline & & $\mathrm{CFD}_{\mathrm{R}}$ & - & 0.919 \\
\hline & & $\mathrm{CFD}_{M}$ & 0.986 & 1.007 \\
\hline & & Experiment & 1.135 & 1.142 \\
\hline & \multirow{4}{*}{ జี } & & $\zeta_{\mathrm{D}}$ & $\zeta_{H}$ \\
\hline & & $\mathrm{CFD}_{\mathrm{R}}$ & - & 0.935 \\
\hline & & $\mathrm{CFD}_{\mathrm{M}}$ & - & - \\
\hline & & Experiment & 1.140 & 1.118 \\
\hline
\end{tabular}

Table 7: Variant E1 and E2 loss coefficients

\section{Variant $\mathbf{F}$}

Four variants of wall slope were tested $-\varphi=10^{\circ}, 15^{\circ}, 20^{\circ}, 25^{\circ}$. The goal was to ensure optimum flow sections after the locking plate using a simple design modification, especially with regard to the removal of problem areas after the locking plate.

\begin{tabular}{|c|c|c|c|c|}
\hline \multirow{13}{*}{ 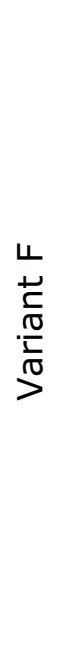 } & \multirow{4}{*}{$\stackrel{\circ}{\circ}$} & & $\zeta_{\mathrm{D}}$ & $\zeta_{H}$ \\
\hline & & $\mathrm{CFD}_{\mathrm{R}}$ & - & 0.825 \\
\hline & & $\mathrm{CFD}_{\mathrm{M}}$ & 1.005 & 1.006 \\
\hline & & Experiment & 1.182 & 1.100 \\
\hline & \multirow{3}{*}{$\stackrel{\text { in }}{\rightarrow-1}$} & $\mathrm{CFD}_{\mathrm{R}}$ & - & - \\
\hline & & $\mathrm{CFD}_{\mathrm{M}}$ & 0.982 & 0.983 \\
\hline & & Experiment & - & - \\
\hline & \multirow{3}{*}{ : } & $\mathrm{CFD}_{\mathrm{R}}$ & - & 1.000 \\
\hline & & $\mathrm{CFD}_{\mathrm{M}}$ & 1.000 & 1.000 \\
\hline & & Experiment & 1.000 & 1.000 \\
\hline & \multirow{3}{*}{$\stackrel{\stackrel{\circ}{N}}{\sim}$} & $\mathrm{CFD}_{\mathrm{R}}$ & - & - \\
\hline & & $\mathrm{CFD}_{\mathrm{M}}$ & 1.013 & 1.046 \\
\hline & & Experiment & - & - \\
\hline
\end{tabular}

Table 8: Variant F loss coefficients

From Table 8 the course of the loss coefficient depending on the angle of the rear wall tilt is not clear. However, it applies in general that smaller angle values are more favourable. A smaller slope means easier flowing of the medium into the area after the locking plate and limitation of a local vortex. 


\section{Variant G}

In comparison with variant $B$, this is a modification of the part of the shape area after the locking plate. The slope of the rear wall is $\varphi=10^{\circ}$. This is therefore a combination of positive results from all previous variants. Vortices are created after the locking plate, but their size is limited against other variants. This also corresponds with the significant decrease of the loss coefficient, the smallest of all achieved results, see Table 9.

\begin{tabular}{|c|c|c|c|}
\hline \multirow{4}{*}{$\begin{array}{l}0 \\
\dot{5} \\
\dot{J}\end{array}$} & & $\zeta_{\mathrm{D}}$ & $\zeta_{H}$ \\
\hline & $\mathrm{CFD}_{\mathrm{R}}$ & - & 0.754 \\
\hline & $\mathrm{CFD}_{\mathrm{M}}$ & 0.963 & 0.944 \\
\hline & Experiment & - & - \\
\hline
\end{tabular}

Table 9: Variant G loss coefficients

In Figure 10, there are velocity magnitude vectors in the parting plane for variant $A$. Two basic vortices are apparent in accordance with Figure 6. Due to the shaping of the parting plane, vortex 1 is strongly limited, which also decreases the loss coefficient, see Figure 11. Vortex 2 is preserved. The modification of this hood part for purpose of vortex 2 is designed in variant $D$.

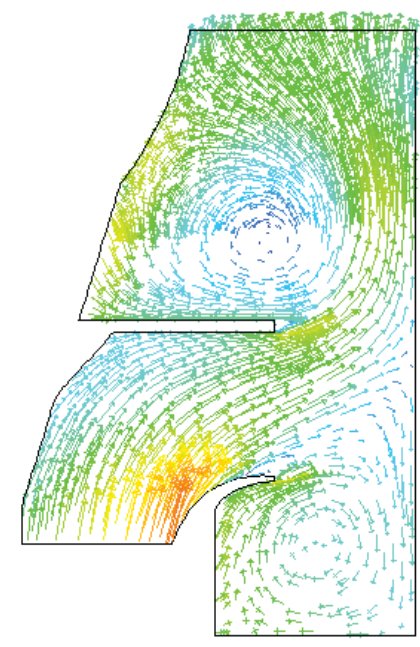

Figure 10: Velocity vectors - variant A

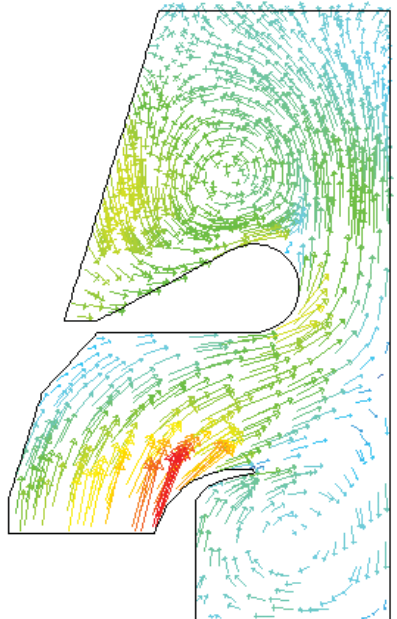

Figure 11: Velocity vectors - variant G

\section{Variant H}

The following combination of designed alternatives can be recommended as the optimum variant. It would be the alternative $\mathrm{G}$ with an optimised area behind the locking plate, using a modified rotor opening and a central partition. The rear wall slope would be $10^{\circ}$. In case of velocity field equalisation at the inlet into the condenser, full boards located under the parting plane along both sides of the body would be used. 


\section{Conclusions}

The presented work deals with the flow in a single flow exhaust hood of a steam turbine. The research was performed using CFD simulations and using measuring on an exhaust hood model. The simulations were performed both on the geometry and with real conditions corresponding with the part and the geometry and edge conditions corresponding with the model device. In certain cases, all three possibilities for the design of the variant in question were not used, especially where further research showed to be unsubstantiated for reason of increasing the losses of the variant in question. The main goal of the work was the modification of the space behind the locking plate and behind the deflector, where large spaces with strong flow whirling and energy losses are created.

An empty hood was chosen as the reference variant. To that a modification of the shape area after the locking plate was designed, obtained on the basis of detailed flow analysis in this point. The variant showed an improvement; however its design difficulty was an obstacle for further research.

Partitions of another designed variant were to prevent the flow behind the locking plate. It showed that the prevention of flow entry just behind the locking plate has a negative effect. Partial suction of the flow and its intensive whirling take place. It is also important mentioning that in this case the flow cross sections in the body and local clogging take place.

The shift of the external body case against the fixed last stage proved to be inappropriate. It removed vortex 2 on one hand, on the other hand, negative effects caused by enlarging vortex 1 began to appear. Vortex 1 had a decisive influence on the drop of the loss coefficient.

The partitions along the sides of the body under the parting plane cause equalisation of the velocity field at the condenser inlet, but the presumed benefit in the efficiency is not remarkable.

The modification of the rear wall slope is important and simple to implement. By changing the angle of the wall, more suitable flow of the steam into the space behind the locking plate occurs. There is smaller whirling and the area also partially acts as a diffuser due to the expansion of the cross section. The recommended angle is $\varphi=10 \div$ $15^{\circ}$.

The last designed variant was the modification of the area behind the locking plate formed only from two simple elements - a shaped pipe and sheet metal. Together with the modification of the rotor opening shape and introduction of the dividing partition, the lowest losses were achieved with this variant.

An exhaust hood with a suitable modification, usable in practice, was designed. Against the reference variant, a decrease of the loss coefficient by $5 \%$ was achieved. By additional blowing into the deflector wall, it is possible to decrease the loss level further by up to $15 \%-[6]$. The necessary reinforcement elements increase the losses in the body by approximately $14 \%$ - [7]. The overall benefit in the efficiency value of a fully equipped body with the performed modifications against an empty body may be around 6 $\%$. 


\section{ACKNOWLEDGEMENT}

The authors of the document wish to thank the Ministry of Industry and Commerce of the Czech Republic for the provision of financial resources for this work within the scope of grant TIP FR-TI3/432.

\section{REFERENCES}

[1] Tajc L., Bednar L., Goudkov E.I.: Exhaust hood of Double-Flow Arrangement; In: 4th European Conference on Turbomachinery, 2001, pp. 161-168, Firenze, Italy.

[2] Tajc L., Bednar L., Poskocilova M., Hoznedl M.: Exhaust Hood for the Steam Turbines of Single - Flow Arrangement; ; In: CPM Turbomachinery, No 122, Symkom' 02, 2002, pp. 371-378, Lodz, Poland.

[3] Tajc L., Bednar L., Poskocilova M., Hoznedl M.: Exhaust Hood for the Steam Turbines of Single - Flow Arrangement; In: CPM Turbomachinery, No 128, Symkom' 05, 2005, pp. 371-378, Lodz, Poland.

[4] Kreitmeier F., Lücking P., Benim Cemal A.: Augmentation of Axial-Radial and Axial-Axial diffusers form improved Design and Off-Design Turbine Performance; In: 7th European Conference on Turbomachinery, 2007, pp. 405-416, Athens, Greece.

[5] Hoznedl M., Tajc L., Bednar L., Krejcik J., Linhart J., Sedlak K.: Exhaust Hood for Steam Turbines - Single Flow Arrangement; In: The 2nd International Symposium on Jet Propulsion and Power Engineering, 2008, pp. 530-537, Guilin, China.

[6] Goudkov E.I., Nikolaev M.A., Ris V.V., Smirnov E.M., Tajc L.: Influence of TipClearance Jet Leakage on Efficiency of Working Fluid Injection into the Diffuser as Applied for Reduction of Exhaust Hood Case; In: 5th European Conference on Turbomachinery, 2003, pp. 761-770.Prague, Czech Republic.

[7] Feldberg L.A., Tajc. L., Bednar L., Sikova I., Goudkov E.I.: The Experimental Investigation of the Influence of the Flow Swirl and the Tip Clearance Jet on Aerodynamic Characteristic of Exhaust Hoods; In: 7th European Conference on Turbomachinery, 2008, pp. 395-404, Athens, Greece.

[8] Зарянкин А.Е., Симонов Б.П.: Выхлопные патрубки паровых и газовых турбин, Издательство МЭИ, 2002, г. Москва. 